\title{
Virtual Reality Games and the Role of Body Involvement in Enhancing Positive Emotions and Decreasing Anxiety: Within-Subjects Pilot Study
}

Federica Pallavicini ${ }^{*}, \mathrm{PhD}$; Alessandro Pepe ${ }^{*}, \mathrm{PhD}$

Department of Human Sciences for Education, University of Milano-Bicocca, Milan, Italy

*all authors contributed equally

Corresponding Author:

Federica Pallavicini, $\mathrm{PhD}$

Department of Human Sciences for Education

University of Milano-Bicocca

Piazza dell'Ateneo Nuovo 1

Milan, 20100

Italy

Phone: 390264484903

Email: federica.pallavicini@gmail.com

\begin{abstract}
Background: In the last few years, the introduction of immersive technologies, especially virtual reality, into the gaming market has dramatically altered the traditional concept of video games. Given the unique features of virtual reality in terms of interaction and its ability to completely immerse the individual into the game, this technology should increase the propensity for video games to effectively elicit positive emotions and decrease negative emotions and anxiety in the players. However, to date, few studies have investigated the ability of virtual reality games to induce positive emotions, and the possible effect of this new type of video game in diminishing negative emotions and anxiety has not yet been tested. Furthermore, given the critical role of body movement in individuals' well-being and in emotional responses to video games, it seems critical to investigate how body involvement can be exploited to modulate the psychological benefits of virtual reality games in terms of enhancing players' positive emotions and decreasing negative emotions and anxiety.
\end{abstract}

Objective: This within-subjects study aimed to explore the ability of commercial virtual reality games to induce positive emotions and diminish negative emotions and state anxiety of the players, investigating the effects of the level of body involvement requested by the game (ie, high vs low).

Methods: A total of 36 young adults played a low body-involvement (ie, Fruit Ninja VR) and a high body-involvement (ie, Audioshield) video game in virtual reality. The Visual Analogue Scale (VAS) and the State-Trait Anxiety Inventory, Form-Y1 (STAI-Y1) were used to assess positive and negative emotions and state anxiety.

Results: Results of the generalized linear model (GLM) for repeated-measures multivariate analysis of variance (MANOVA) revealed a statistically significant increase in the intensity of happiness $(P<.001)$ and surprise $(P=.003)$ and, in parallel, a significant decrease in fear $(P=.01)$ and sadness $(P<.001)$ reported by the users. Regarding the ability to improve anxiety in the players, the results showed a significant decrease in perceived state anxiety after game play, assessed with both the STAI-Y1 $(P=.003)$ and the VAS-anxiety $(P=.002)$. Finally, the results of the GLM MANOVA showed a greater efficacy of the high body-involvement game (ie, Audioshield) compared to the low body-involvement game (ie, Fruit Ninja VR), both for eliciting positive emotions (happiness, $P<.001$; and surprise, $P=.01$ ) and in reducing negative emotions (fear, $P=.05$; and sadness, $P=.05$ ) and state anxiety, as measured by the STAI-Y1 $(P=.05)$.

Conclusions: The two main principal findings of this study are as follows: (1) virtual reality video games appear to be effective tools to elicit positive emotions and to decrease negative emotions and state anxiety in individuals and (2) the level of body involvement of the virtual video game has an important effect in determining the ability of the game to improve positive emotions and decrease negative emotions and state anxiety of the players.

(JMIR Serious Games 2020;8(2):e15635) doi: 10.2196/15635 


\section{KEYWORDS}

virtual reality; virtual reality gaming; video games; emotions; positive emotions; anxiety; state anxiety

\section{Introduction}

\section{Background}

As stated by Bowman and Tamborini [1], "Video games can't be understood divorced from their role as technology that persistently pushed the limits of communication." While in the 1970s, video games first emerged as simple activities that involved using a keyboard or dial to control tiny black and white objects on the screen, today's computer games are increasingly and dramatically advanced in terms of both graphics and interaction.

One of the most important points in time in the evolution of contemporary gaming is represented by the entry into the mass market of virtual reality video games in the last few years, following the mass diffusion of commercial head-mounted display (HMD) devices, such as Oculus Rift (Facebook Technologies), Vive (HTC Corporation), and PlayStation VR (Sony Interactive Entertainment) [2]. The popularity of virtual reality video games is continuously growing among users: in 2019, Oculus Quest, the first stand-alone headset (ie, it does not require any external device to work) sold out across multiple stores a week after launching [3]; as well, for the first time, the number of connected virtual reality users on the online gaming platform Steam had surpassed 1 million, as determined by data captured over the course of a month [4].

Compared to more traditional (ie, desktop display device) video games, virtual reality games have profoundly different characteristics $[2,5,6]$. In particular, one of the main relevant differences is the level of immersion, defined as a "quantifiable description of a technology, which includes the extent to which the computer displays are extensive, surrounding, inclusive, vivid and matching" [7]. Technologies can immerse their users in a virtual environment to different degrees, from a simple nonimmersive presentation on a computer screen (ie, desktop displays) to immersive systems, such as HMDs like Oculus Rift (Facebook Technologies) or Vive (HTC Corporation) [2]. The sense of immersion into mediated computerized environments, in general, and computer games, in particular, has previously been explained through spatial presence and flow [8,9]. Even if these concepts share conceptual similarities, such as immersive components and intense feelings, they refer to different theoretical constructs [8]. In particular, while presence relates to a sense of spatial immersion in a mediated environment [10], flow is generally defined as the optimal experience when nothing else matters $[11,12]$. With respect to computer games, flow has been defined as the sensation of influencing the activity in the virtual world (ie, gaming in action) [13], and it is recognized as a central element of exciting gaming experiences $[14,15]$.

Interestingly, scientific studies have recently started to recognize the potential positive impact of virtual reality video games on people's health (eg, $[16,17])$ and cognitive abilities (eg, $[18,19])$. For example, a previous study [18] has reported the efficacy of a virtual reality exercise-based dance game, DANCE, that was created ad hoc by researchers for the training of executive functions in older people. In addition, another recent study [19] showed the feasibility of using a commercial virtual reality game to assess executive functions and cognitive abilities, as measured by a traditional neuropsychological test, the Trial Making Test (TMT) [20]. The results showed that user performance in the dance game Audioshield (Dylan Fitterer) predicted the TMT scores (ie, time to complete TMT-A and TMT-B) [19].

Not only are virtual reality video games potentially useful tools for the assessment and training of cognitive abilities, recent studies have also reported that they can be effective tools for people's emotional well-being. In fact, previous studies have suggested that virtual reality video games induce more emotion than do games with less-immersive technologies, such as those on a desktop display device (eg, [2,6,21-23]). With few exceptions [24,25], a higher intensity of emotional response has been observed in virtual reality games compared to desktop games, at both a psychological and a physiological level [2,6,21-23]. For example, players reported a more intense emotional experience while playing the first-person shooter (FPS) game Half-Life 2 (Valve Corporation) in an immersive modality through an HMD compared to playing the same game on a monitor [22].

However, less is known about the ability of a virtual reality game to elicit positive emotions and decrease negative emotions and anxiety in the players, because specific studies on that subject have not yet been conducted.

\section{Virtual Reality Video Games, Positive Emotions, and Relaxation}

One of the most commonly reported motives for playing modern video games is the pleasure offered by digital games: people look for and are more willing to buy games that elicit positive emotions [26-28]. Positive emotions are considered to form the basis for the growing and flourishing self [29] and are especially important in increasing the level of subjective well-being [29-31]. As stated by broaden-and-build theory [32-34], “...certain discrete positive emotions-including joy, interest, contentment, pride, and love-although phenomenologically distinct, all share the ability to broaden people's momentary thought-action repertoires and build their enduring personal resources, ranging from physical and intellectual resources to social and psychological resources" [34].

Several studies have shown that computer games played on desktop display devices can generate positive emotions, such as joy or happiness (eg, [35-37]). For example, in a study investigating event-specific emotional responses while playing Super Monkey Ball 2 (SEGA) — a platform game (ie, a subgenre of an action game) where the player controls a character who has to jump and climb between suspended platforms while avoiding obstacles - players who experienced not only positive events (eg, acquiring in-game goods) but also some negative events (eg, falling over the edge of the game board) were 
reported to elicit positively valenced arousal [26]. In another study, predominantly positive emotions were reported while playing the action game Counter-Strike (Valve Corporation), as assessed by an electroencephalogram (EEG) alpha index; in addition, subjective ratings of emotional responses indicated happiness, both during and after the game [37]. Furthermore, dopamine, a neurotransmitter linked to sensations of pleasure and reward, has been detected using positron emission tomography (PET) during video game playing [38]. In addition, regular players have advocated video game play as a means of relaxation [39-41], and the search for distraction and escapism is among the most often reported motives for playing video games [42-44].

Different types of desktop video games have been reported to be effective in decreasing anxiety in individuals, inducing a state of relaxation (eg, [45-49]) and positive emotions [50]. For example, video games characterized by low cognitive load and generally short time demands, such as Tetris (Nintendo) or Angry Birds (Rovio Entertainment Corporation), have proven to be able to diminish state anxiety $[51,52]$ as well stress in players [41], even more effectively than traditional techniques, such as medical treatment $[51,52]$ or guided meditation $[53,54]$.

Interestingly, some recent studies have reported a greater increase in positive emotions after playing a virtual reality game compared to a game on a desktop display $[2,23,55]$. For instance, players showed a higher level of happiness and surprise, as assessed by self-report questionnaires, after playing an FPS game (ie, Smash Hit [Mediocre AB]) in virtual reality versus after playing the same game on a desktop display [2]. In addition, while the perceived feeling of happiness increased after playing the bestselling survival horror game Resident Evil: BioHazard (Capcom) in virtual reality, the opposite result was obtained after desktop gameplay, specifically, a decrease in the sense of happiness in comparison to the baseline [55].

Thanks to virtual reality's unique features of immersion and body involvement [56,57], virtual reality games seem to be appealing new tools to elicit positive emotions and to decrease anxiety in individuals. However, until now, no study has been conducted specifically to test the ability of this new type of interactive video game to enhance positive emotions and to decrease negative emotions and anxiety in individuals.

\section{Body Involvement and Psychological Benefits of Video Games}

In addition to differences in terms of immersion, what strongly distinguishes virtual reality video games from traditional ones is that in virtual reality, the movement of the player's body itself becomes the main interface for interacting with the virtual world $[2,58,59]$. In a virtual reality video game, in fact, the player can interact with virtual content not only through a joypad or a keyboard but also by using head rotation, eye movements, or specially designed controllers that respond to the position and movements of the player in a defined space [2]. Depending on the specific video game and virtual reality system adopted, the player's level of body involvement can vary significantly. For example, in Smash Hit VR (Mediocre AB), which is compatible with the HMD Gear VR (Samsung), it is possible to interact in the game using only head movements. In contrast, in other titles, such as Beat Saber (Beat Games) or Superhot VR (SUPERHOT Team), the movement of the whole body is required to play the game.

Studies from various disciplines have investigated the relationship between body movement and well-being, showing that body movement affects emotional processes, with an almost immediate antianxiety and antidepressive effect [60-64] and with long-term positive outcomes on physical health [65-68].

Interestingly, previous studies have reported that an increased involvement of the body while playing video games on desktop displays leads to more intense emotional and affective responses by the player $[69,70]$. Furthermore, recent preliminary studies have reported that exergames - ones that are considered a combination of video gaming and physical exercise requiring physical effort from the player in order to play the game [71-73] — are able to elicit positive emotions among older adults [71], inducing higher positive emotions than traditional exercise [74], and are able to reduce state anxiety in a nonclinical sample of healthy women [75].

These considerations about the critical role of body movement in individuals' well-being and in emotional responses to video games make it critical to understand how body involvement can be exploited to modulate the psychological benefits of virtual reality games in terms of enhancing players' positive emotions and decreasing their negative emotions and anxiety.

\section{Study Objectives}

Within the context described above, this within-subjects study aimed to explore the ability of commercial virtual reality games to induce positive emotions and diminish state anxiety of the players, investigating the effects of the level of body involvement requested by the game (ie, high vs low).

The main hypotheses of this study were as follows:

1. Hypothesis 1: Video games played in virtual reality will increase self-reported positive emotions (ie, joy and happiness) and will reduce negative emotions (ie, fear and sadness) and perceived state anxiety.

2. Hypothesis 2: A game with high body involvement (ie, Audioshield [Dylan Fitterer]) will elicit stronger positive emotions and a more intense decrease in negative emotions and state anxiety compared to a game with low body involvement (ie, Fruit Ninja VR [Halfbrick Studios]).

\section{Methods}

\section{Participants}

The execution of the experiment occurred between July and October 2018. No credits or economic rewards were provided during the research. Participants were recruited from among the students and personnel of the University of Milano-Bicocca and other universities in Milan, Italy, via flyers distributed to campuses and word of mouth. In order to be included in the study, individuals had to meet the following criteria: (1) be aged between 18 and 35 years, (2) have no significant visual impairment (ie, all with normal or corrected-to-normal visual acuity), and (3) have no previous experience with the video games selected for the study (ie, Audioshield or Fruit Ninja 
$V R$ ). With regard to the size of the sample, a power sample analysis was conducted with a level of statistical significance equal to $5 \%$, power set at $80 \%$, and a medium-sized effect (ie, 0.50 ) expected at the upper bound [76]. An effect size equal to 0.50 corresponded to a $66 \%$ probability that persons from a given condition would experience a higher effect than persons from the other condition, if both were chosen at random. In addition, the effect size value of 0.50 was in line with other similar studies in the field of virtual reality in relation to emotional domains that highlighted a magnitude of effect size that can be considered medium to large. As a result, the suggested sample size for this kind of analysis and research design was set to 34 . Before participating, all participants were provided with written information about the study and were required to give written informed consent in order to be included. The study received ethical approval from the Ethical Committee of the University of Milano-Bicocca. The research was conducted in accordance with the American Psychological Association's 2010 ethical principles and code of conduct. A total of 39 individuals were assessed for eligibility to participate in the study: 3 were excluded (8\%) due to not meeting inclusion criteria and no subjects declined to participate. The final sample included 36 participants: 13 females (36\%) and 23 males (64\%); mean age of 25.6 years (SD 4.18); and mean length of education of 15.9 years (SD 3.1).

\section{Psychometric Assessment}

At the beginning of the experimental session, a self-report questionnaire was given to participants that included the following items:

1. Demographics: participants were asked to indicate their gender (female or male), their age, and their years of education.

2. Gaming habits and previous virtual reality experience: individuals were asked to report on their gaming habits (ie, mean hours spent gaming per week) and to assess their previous experience with virtual reality systems on a 7-point Likert scale ranging from 1 (not at all) to 7 (very much).

In addition, to assess the self-reported indexes concerning positive and negative emotions as well as state anxiety, the following questionnaires were used:

1. Visual Analogue Scale (VAS) [77]: this scale consists of a horizontal line, $10 \mathrm{~cm}$ in length, anchored by word descriptors at each end. Participants marked the point on the line - from 0 to 100 - that they felt visually represented their perception of their current level of happiness (VAS-HP), surprise (VAS-SP), fear (VAS-FE), sadness (VAS-SD), and anxiety (VAS-A). A large number of studies have confirmed the reliability and validity of VAS measurements (eg, [78-81]).

2. State-Trait Anxiety Inventory, Form-Y1 (STAI-Y1) [82-84]: individuals were asked to specify to what extent, on a 4-point Likert scale ranging from 1 (not at all) to 4 (very much), they perceived at that moment each of the 20 indicated feelings. The STAI-Y1 scale has high internal consistency, with a Cronbach $\alpha$ coefficient ranging from .86 to $.95[83,85,86]$; this is considered a reliable measure to capture rapid state-dependent variations in anxiety $[85,86]$.

\section{Video Games}

The video games tested in the study were as follows:

1. Audioshield (Dylan Fitterer): this is a virtual reality exergame launched in April 2016 for Vive (HTC Corporation). This title is a dance game in which orbs come flying toward the player, who needs to follow the beat of the music to successfully hit them. The player uses Vive's handheld motion-sensing controls to operate two shields, blue and red: red balls must be deflected with the red shield controlled by the right hand, while blue balls must be deflected with the left hand; purple orbs require a combination of both arms. During the game, the color and the direction of the orbs that the player has to hit changes continuously; for example, the blue balls can come from the right, or red from the left, and require the user to respond correctly very quickly.

2. Fruit Ninja VR (Halfbrick Studios): this game represents the 2016 virtual reality version of the bestselling video game Fruit Ninja (Halfbrick Studios), a 2010 game for mobile devices where players were required to hit fruit by dragging their finger on the screen. In Fruit Ninja VR-a game compatible with Vive (HTC Corporation), Oculus Rift (Facebook Technologies), and PlayStation VR (Sony Interactive Entertainment) - the players used the handheld motion-sensing controls as swords to slice fruits, sitting or standing, and simulating slashes as if they were performing them in real life. The goal was the same as in the mobile version: cut the fruit, do not let it fall, and avoid the bombs in order to collect as many points as possible and climb the rankings.

These video games were selected since, despite the common aim of both games to hit objects that appear in front of the player, they differ profoundly in terms of the body movement required by the game. In particular, while Audioshield requires the player to move the whole body in the game space (eg, lateral movements to avoid obstacles and arm movements to hit the balls), in Fruit Ninja VR the interaction takes place only through the movements of the superior limbs. In this title, in fact, the position of the feet and superior limbs are fixed at a certain point in space, indicated graphically within the game.

Regarding the hardware, both video games were played on the same virtual reality setting, which included the following units (see Multimedia Appendix 1):

1. Vive system (HTC Corporation): a consumer-grade virtual reality system designed for use in video games. This system consists of an HMD, two controllers, and two infrared laser-emitter units. The headset offers a nominal field of view of about 110 degrees (approximately 90 per eye) through two $1080 \times 1200$-pixel displays that are updated at $90 \mathrm{~Hz}$. Games played with the Vive system allow physical movement within a play area that is limited to $4 \times 4$ meters.

2. A portable computer: MSI (Micro-Star International) GT73VR, Intel Core i7 processor, GeForce GTX 1070 8GB, 
17.3-inch full HD (high-definition) 1920×1080-pixel display.

\section{Experimental Design}

A within-subjects design was used to compare the emotional response, in terms of self-reported positive and negative emotions, and the perceived sense of anxiety among participants in the two experimental conditions. Specifically, the study compared the following:

1. High body-involvement condition (Audioshield): after a brief explanation of the video game by the experimenter, the participants were asked to play for about 5 minutes-2 minutes of practice using the song Engage (difficulty: normal; shield: gladiator; environment: horizon), followed by 3 minutes of play to complete the song I Drop Gems (difficulty: normal; shield: gladiator; environment: horizon).

2. Low body-involvement condition (Fruit Ninja VR): the participants were asked to play for about 5 minutes-2 minutes of practice using the Zen mode of the video game; individuals were then asked to play twice in the classic mode, where they had to cut as much fruit as possible and prevent it from falling to the ground and losing a life: players spent a mean of 78 seconds (SD 18) for each play.

\section{Procedure}

After individuals gave written informed consent to participate, they completed the self-report questionnaire assessing demographics, gaming habits, and virtual reality knowledge, as well as the VAS-HP, VAS-SP, VAS-FE, VAS-SD, VAS-A, and STAI-Y1. Once this phase was completed, the Vive system was connected to the PC through a 5-meter cable with an HDMI (high-definition multimedia interface) connection and a USB 2.0 connection, and the system was connected to a power source. Participants were asked to wear the HMD and were given the Vive system controllers.

The audio level was set to 45 for all participants. Subjectively, tracking appeared stable when using this configuration, and the video game was playable with no visible tracker artifacts. All measurements were taken in an $8 \times 5$-meter room with a 3.2-meter-high ceiling lighted by fluorescent lighting with no reflective surfaces and no exposure to natural light. In the center of this room, a $4 \times 4$-meter grid (ie, the play area) was drawn on the floor using string and chalk, with grid lines drawn 1 meter apart. Participants were randomly assigned to start with either the high $(\mathrm{n}=18)$ or the low $(\mathrm{n}=18)$ body-involvement condition; the conditions were counterbalanced for the total individuals through an established randomization scheme obtained from the Research Randomizer website [87] run by one of the researchers involved in the study before the start of the experiments. After completing each gameplay mode, participants again answered the following self-reported questionnaires: the VAS-HP, VAS-SP, VAS-FE, VAS-SD, VAS-A, and STAI-Y1. The complete experience lasted about 40 minutes long (see Figure 1). 
Figure 1. Flowchart of the study procedure. STAI-Y1: State-Trait Anxiety Inventory, Form-Y1; VAS-A: Visual Analogue Scale-anxiety; VAS-FE: Visual Analogue Scale-fear; VAS-HP: Visual Analogue Scale-happiness; VAS-SD: Visual Analogue Scale-sadness; and VAS-SP: Visual Analogue Scale-surprise.

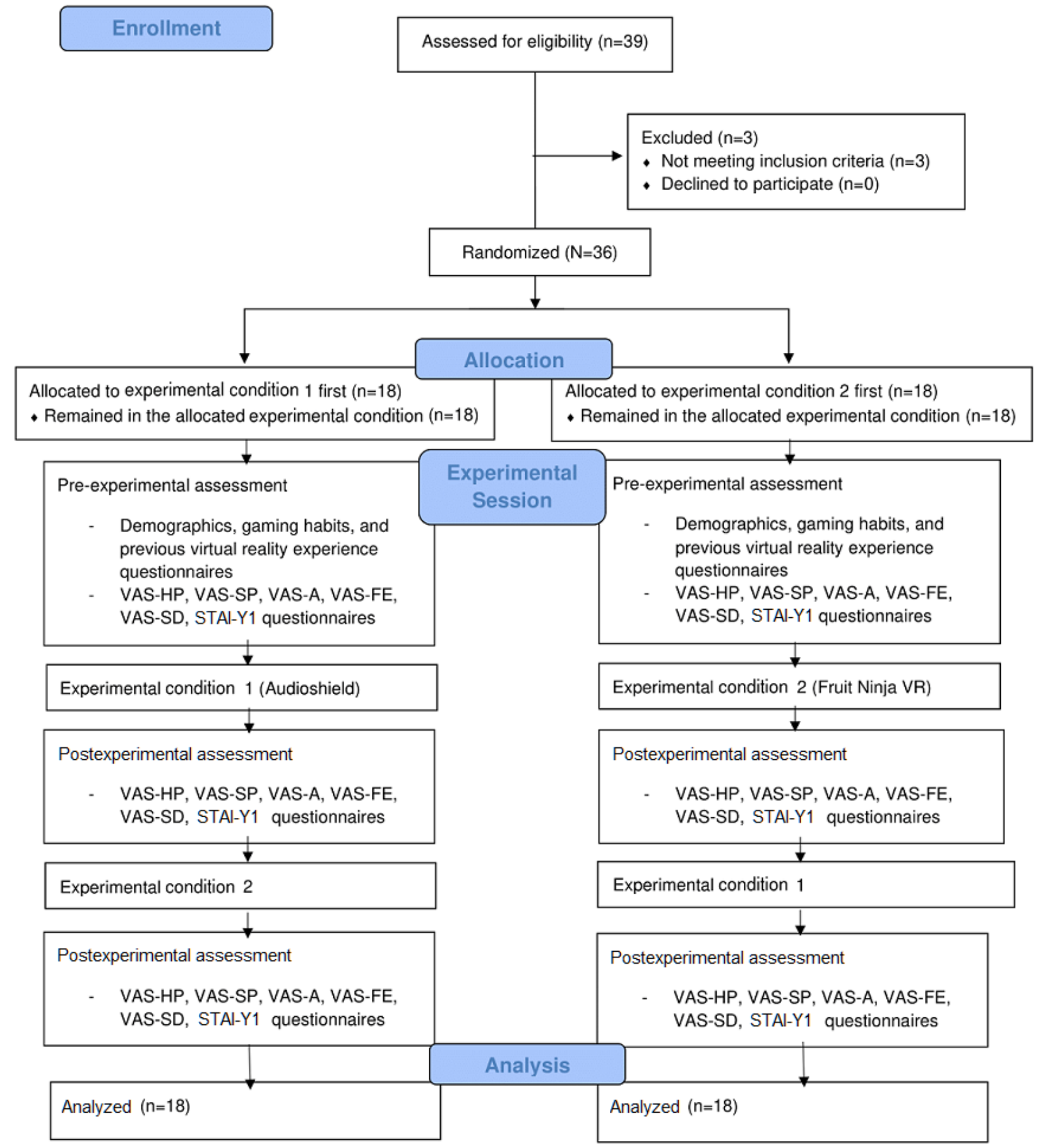

\section{Strategy of Data Analysis}

Data were analyzed by means of a set of multivariate statistical tests. First, common assumptions (ie, normality, homogeneity of variance, and homoscedasticity) for multivariate analysis were assessed and procedures of data cleaning (ie, missing-values analysis and detection of uni- and multivariate outliers) were conducted. In general, no major violations to assumptions were found and a multivariate outlier was skipped. Multivariate outliers were identified by computing Mahalanobis distances, and the $P$ value was set to be equal to .001 .
In order to explore our research hypotheses, different series of generalized linear models (GLMs) were performed. For hypothesis 1, a GLM model for repeated-measures multivariate analysis of variance (MANOVA) was tested by including the four VAS measures related to positive (eg, happiness and surprise) and negative (eg, fear and sadness) emotions. Then, a second model was tested by including the two measures (eg, VAS-A and STAI-Y1 scores) of state anxiety. Such analysis is useful in measuring the effect of a treatment at different time points and in different groups. Furthermore, the GLM enabled evaluation of the main effect within and between the subjects as well as interaction effects between factors. Finally, the GLM 
estimated the magnitude of effect sizes for all variables. In this study, the GLMs were conducted in such a way that pre- and postexperiment measures were the within-subjects factors (ie, three levels), whereas the condition (ie, high vs low body-involvement video game) was the between-subjects factor. The interactive effect within $\times$ between was included in the model. For testing hypothesis 2, two GLMs were conducted in order to compare whether pre- and postexperiment differences in target variables (ie, positive emotion as well as negative emotion and anxiety) were statistically significant when low body-involvement and high body-involvement games were compared, once controlled for the order of presentation. For all tested models, effect size was reported $\left(\eta^{2}\right)$. According to Cohen [88], effect size should be considered small for values 0.20 and lower, medium for values between 0.21 and 0.50 , and large for values of 0.51 and higher.

\section{Results}

\section{Descriptive Characteristics of Participants}

Gaming habits and the previous virtual reality experience of the sample are summarized in Table 1. Zero-order correlations between positive emotions, negative emotions, and anxiety scores are presented in Multimedia Appendix 2.

Table 1. Descriptive characteristics of the sample's gaming habits and previous experience with virtual reality.

\begin{tabular}{ll}
\hline Characteristic & Mean (SD) \\
\hline Hours spent gaming per week & $9.5(10.9)$ \\
Previous experience with virtual reality $^{\mathrm{a}}$ & $5.1(2.8)$ \\
\hline
\end{tabular}

${ }^{\text {a }}$ Rated on a 7-point Likert scale ranging from 1 (not at all) to 7 (very much).

\section{Psychological Assessment}

Starting from hypothesis 1 of this study, the GLM for the repeated-measures MANOVA was used to test whether video games played in virtual reality increased self-reported positive emotions (ie, VAS-SP and VAS-HP) and reduced negative emotions (ie, VAS-FE and VAS-SD) and perceived state anxiety (ie, VAS-A and STAI-Y1).

Generally speaking, the GLM testing differences among emotional scores (ie, VAS-SP, VAS-HP, VAS-FE, and VAS-SD) revealed a within-subjects statistically significant effect $\left(F_{8,27}=9.64, P<.001, \eta^{2}=.741\right)$. On the contrary, the effect of the between-subjects condition (ie, low vs high body-involvement game as first stimulus) reported a nonstatistically significant effect $\left(F_{8,27}=0.56, P=.80, \eta^{2}=.143\right)$, meaning that regardless of the order of presentation, there were differences in emotional levels between the baseline values and the scores obtained after a playing session. In particular, the domain of positive emotions reported statistically significant effects for both the VAS-SP $\left(F_{8,27}=7.93, P=.003, \eta^{2}=.189\right)$ and the VAS-HP $\left(F_{8,27}=11.62, P<.001, \eta^{2}=.255\right)$. In both cases, the scores on the high body-involvement game were higher if compared to both baseline and the low body-involvement game. Univariate tests in relation to negative emotions reported a statistically significant effect for both the VAS-FE $\left(F_{8,27}=5.13\right.$, $\left.P=.01, \eta^{2}=.131\right)$ and the VAS-SD $\left(F_{8,27}=10.06, P<.001\right.$, $\left.\eta^{2}=.228\right)$, meaning that negative-emotion levels were lower in high body-involvement games than what was reported at baseline and in low body-involvement games (see Multimedia Appendix 3).

Regarding self-reported state anxiety (ie, STAI-Y1 and VAS-A), the results of the GLM revealed a within-subjects statistically significant effect $\left(F_{4,31}=4.58, \quad P=.005, \quad \eta^{2}=.372\right)$. A nonstatistically significant effect was found in terms of presentation order between the different games $\left(F_{2,33}=0.01\right.$, $\left.P=.99, \eta^{2}=.001\right)$. Univariate tests revealed that both the VAS-A $\left(F_{4,31}=8.01, P=.002, \eta^{2}=.191\right)$ and the STAI-Y1 $\left(F_{4,31}=6.45\right.$, $\left.P=.003, \eta^{2}=.160\right)$ reported statistically significant effects, meaning that the two measures of state anxiety converged in cross-validating the idea of a reduction of anxiety levels in players during virtual reality gaming sessions (see Figure 2). As a result, the findings supported the acceptance of hypothesis 1. 
Figure 2. Mean scores of the Visual Analogue Scale-anxiety (VAS-A) and the State-Trait Anxiety Inventory, Form-Y1 (STAI-Y1). The VAS-A is measured on a scale consisting of a horizontal line, $10 \mathrm{~cm}$ in length, with scores ranging from 0 to 100 . The STAI-Y1 is measured on a 4-point Likert scale ranging from 1 (not at all) to 4 (very much). C1: Condition 1, Fruit Ninja VR first; and C2: Condition 2, Audioshield first.

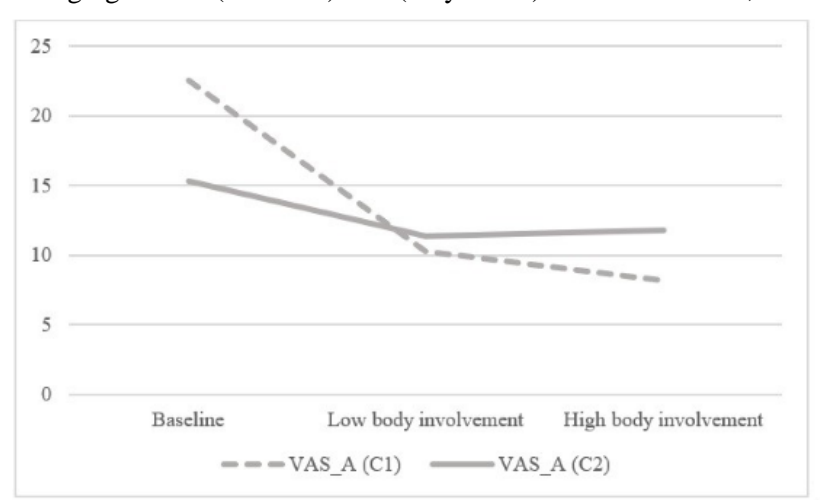

With regard to hypothesis 2, the GLM MANOVA was used to test whether, and to what extent, the psychometric scores of self-reported positive and negative emotions (ie, VAS-SP,

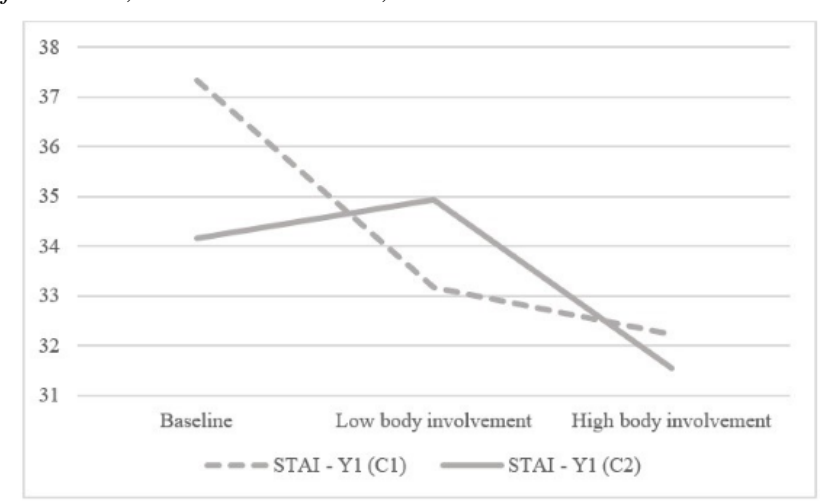

VAS-HP, VAS-FE, and VAS-SD) and state anxiety (ie, VAS-A and STAI-Y1) were related to playing low body-involvement or high body-involvement games (see Table 2).

Table 2. Self-reported emotions and anxiety scores among subjects in the experimental conditions.

\begin{tabular}{|c|c|}
\hline Questionnaire and conditions & Mean (SD) \\
\hline \multicolumn{2}{|c|}{ Visual Analogue Scale-happiness } \\
\hline Baseline & $62.3(20.1)$ \\
\hline High body involvement & $77.6(20.4)$ \\
\hline Low body involvement & $68.2(24.2)$ \\
\hline \multicolumn{2}{|l|}{ Visual Analogue Scale-surprise } \\
\hline Baseline & $50.0(31.6)$ \\
\hline High body involvement & $66.9(29.2)$ \\
\hline Low body involvement & $57.8(30.8)$ \\
\hline \multicolumn{2}{|l|}{ Visual Analogue Scale-fear } \\
\hline Baseline & $8.05(11.7)$ \\
\hline High body involvement & $1.72(4.29)$ \\
\hline Low body involvement & $2.69(6.11)$ \\
\hline \multicolumn{2}{|l|}{ Visual Analogue Scale-sadness } \\
\hline Baseline & $10.1(15.2)$ \\
\hline High body involvement & $2.36(5.91)$ \\
\hline Low body involvement & $5.27(10.6)$ \\
\hline \multicolumn{2}{|l|}{ Visual Analogue Scale-anxiety } \\
\hline Baseline & $18.8(16.8)$ \\
\hline High body involvement & $10.4(13.6)$ \\
\hline Low body involvement & $10.8(12.6)$ \\
\hline \multicolumn{2}{|c|}{ State-Trait Anxiety Inventory, Form-Y1 } \\
\hline Baseline & $35.7(8.00)$ \\
\hline High body involvement & $31.8(7.44)$ \\
\hline Low body involvement & $34.1(7.91)$ \\
\hline
\end{tabular}

The GLM testing between-game differences in emotional scores revealed a within-subjects statistically significant effect $\left(F_{4,31}=3.86, P=.01, \eta^{2}=.333\right)$. On the contrary, the effect of the between-subjects condition (eg, low body-involvement vs high http://games.jmir.org/2020/2/e15635/ body-involvement game as first stimulus) reported a nonstatistically significant effect $\left(F_{4,31}=0.41, P=.72, \eta^{2}=.050\right)$, meaning that regardless of the order of presentation, there were differences in emotional levels between the two games. 
Univariate tests regarding positive emotions reported statistically significant effects for both the VAS-HP $\left(F_{4,31}=12.43, P<.001\right.$, $\left.\eta^{2}=.268\right)$ and the VAS-SP $\left(F_{4,31}=6.83, P=.01, \eta^{2}=.167\right)$. In both cases, the differential scores on the high body-involvement game were higher if compared to scores obtained in the low body-involvement game. Univariate tests in relation to negative emotions reported a statistically significant effect for both the VAS-FE $\left(F_{4,31}=3.47, \quad P=.05, \quad \eta^{2}=.099\right)$ and the VAS-SD $\left(F_{4,31}=5.91 P=.05, \eta^{2}=.148\right)$, meaning that decrements in negative-emotion levels were more relevant in the high body-involvement game than what was reported after the low body-involvement game.

Regarding state anxiety scores, the result of the GLM revealed a within-subjects, statistically significant effect $\left(F_{2,33}=48.25\right.$, $\left.P=.01, \eta^{2}=.334\right)$. A nonstatistically significant effect was found in terms of presentation order between different games $\left(F_{2,33}=2.62, P=.09, \eta^{2}=.132\right)$. Univariate tests revealed that especially for STAI-Y1 scores $\left(F_{2,33}=5.41, P=.05, \eta^{2}=.137\right)$, playing in high body-involvement games lead to a greater reduction of anxiety levels. On the contrary, the VAS-A $\left(F_{2,33}=0.055, \quad P=.82, \eta^{2}=.002\right)$ did not report statistically significant effects. The results supported the acceptance of hypothesis 2, meaning that a greater increase in positive emotions, as well as a reduction of negative emotions and anxiety levels, were found in players after a high body-involvement virtual reality game session.

\section{Discussion}

\section{Principal Findings}

To summarize, the two main principal findings of this study are as follows:

1. Virtual reality video games appear to be effective tools to elicit positive emotions and to decrease negative emotions and state anxiety in individuals.

2. The level of body involvement of the virtual video game has an important effect in determining the ability of a game to improve positive emotions and decrease negative emotions and state anxiety of the players.

The results that emerged from this study appear to support the first main hypothesis (ie, the video games played in virtual reality will increase self-reported positive emotions and will be able to reduce negative emotions and perceived state anxiety). In particular, results of the GLM repeated-measures MANOVA revealed a statistically significant increase in the intensity of happiness and surprise and, in parallel, a significant decrease of fear and sadness reported by the users. Regarding the ability to improve anxiety levels in the players, the results showed a significant decrease in perceived state anxiety after game play, assessed with both the STAI-Y1 and the VAS-A.

Regarding the second main hypothesis (ie, the higher the body movement, the more the game will elicit stronger positive emotions and a more intense decrease in negative emotions and state anxiety), the results of the GLM MANOVA showed a greater efficacy by the high body-involvement game (ie, Audioshield) versus the low body-involvement game (ie, Fruit Ninja $V R$ ) to both elicit positive emotions and reduce negative emotions and state anxiety, as measured by the STAI-Y1.

\section{Potential for Virtual Reality Gaming to Elicit Positive Emotions and Decrease Anxiety}

The ability of virtual reality content to elicit positive emotions and a state of relaxation has been widely demonstrated in relation to virtual environments designed ad hoc by researchers for emotional induction, both in healthy individuals (eg, [89-91]) and in patients suffering from different mental conditions, including anxiety disorders (eg, [92, 93]). This feature has been adopted extensively to improve individuals' well-being, since, as stated by the broaden-and-build model [34], positive emotions provide the organism with nonspecific action tendencies that can lead to adaptive behavior, such as being more likely to interact with others or engage in creative challenges [94,95]. Therefore, as underlined by the positive technology approach [96], technology, including virtual reality, can be an effective tool to improve the quality of people's personal experiences [97].

Interestingly, what emerges from this study shows that not only virtual content specifically created for emotional induction but also commercial content such as virtual reality video games can be effective in inducing positive emotions and decreasing negative emotions and anxiety in individuals. Such a result appears in line with what has been reported recently, with a few exceptions [24], about the ability of virtual reality video games to elicit positive emotions such as joy in the players and to do so with a more intense effect than that of desktop video games $[2,6,21]$. Besides, according to the results of this study, virtual reality video games are able to not only elicit positive emotions but also decrease negative emotions (ie, sadness and fear) and state anxiety in the players.

If the results of this study are confirmed by future research, they might represent positive evidence for the adoption of virtual reality games, not just for entertainment purposes but also in the mental health panorama. Given that positive emotions are linked strongly to the use of technological products and the user's overall level of satisfaction with them-as underlined by emotional design $[98,99]$, a conceptual framework that is largely adopted in the context of developing interactive technologies $[100,101]$ — virtual reality video games could be particularly appealing to users. Thanks to their being cost-effective, noninvasive, and nonassociated with stigma or with known side effects, virtual reality video games could offer many advantages compared to classic interventions for improving psychological well-being and decreasing anxiety, such as medication treatment, guided meditation, or cognitive behavioral therapy. In addition, virtual reality games also have several advantages compared to video games played on desktop displays, including the characteristic of requiring higher involvement both at the motor and cognitive levels and a greater engagement compared to nonimmersive games $[17,55]$. They also offer the possibility of collecting a wide variety of data, such as those about the player's movement within the virtual environment. 
Furthermore, the fact that, in this study, these results were observed after a short period of play (ie, about 5 minutes for each video game) could suggest that even very brief interventions with games in virtual reality can be effective ways to increase players' positive emotions and decrease negative emotions and state anxiety. Since the length of the interventions with video games to enhance positive emotions and relaxation vary in the literature [56], with an average of 20-25 minutes of total gameplay (eg, $[46,47])$, the results obtained by this study could represent an element to broaden the reflection on this important topic, and further research is needed.

\section{Significance of the Body's Involvement on Players' Psychological Benefits}

Differences were observed in this study regarding the ability to elicit positive emotions and decrease negative emotions and state anxiety, as measured by the STAI-Y1, depending on the level of body movement requested by the game; this offers interesting insights on the role of body involvement in determining the psychological benefits of video games.

In particular, we observed a greater efficacy of the game that required high body involvement (ie, Audioshield) compared to the game with low body involvement (ie, Fruit Ninja VR). Such results appear to be consistent with previous literature reporting that an increased involvement of the body can afford the player not only a greater level of enjoyment but also a stronger emotional experience [69,70]. In the specific case of virtual reality video games, it could be hypothesized that this effect is related to the ability of body movements to enhance sense of presence [102]. However, other studies have not reported a direct effect of body involvement on sense of presence during virtual reality content [103]. Therefore, future studies should investigate this topic further.

If the results observed in this study are confirmed by future studies, it could represent valid evidence that virtual reality video games, especially those that require a high level of involvement of the player's body, promote emotional well-being in individuals. For example, it would be interesting to test the effects of a virtual reality-based exergame, a type of video game that has proven to be effective for emotional relief and for its antidepressant effect when played on desktop displays [65-67,104, 105].

\section{Limitations}

Although the results of this study could be interesting for their possible applications, this research has some important limitations that prevent a robust generalization of the findings. First, the design of the study did not include a control group (ie, a no-video-game condition). Second, in this study no physiological measure related to emotional responses (eg, heart rate variability and skin conductance responses) and/or state anxiety (eg, parasympathetic activity and cortisol level) were examined. Third, the video games were played for short time periods (ie, about 5 minutes each), and only short-term changes were considered. Finally, it is important to underline the small sample size and the specificity of the included sample (ie, young adults who played several hour per week and had medium-level knowledge of virtual reality systems). All in all, even if the results of this research can be considered promising, due to major limitations, including the probability of being underpowered, robust conclusions were still hard to achieve. In future research, it would be interesting, for example, to widen the sample in order to balance participants on the basis of their level of experience with video games and to collect baseline measures on whether they enjoy exercise in general.

\section{Conclusions}

On the basis of what emerged in this study, and as underlined in previous research $(\mathrm{eg},[56,106])$, the research question no longer seems to need to ask whether video games are good or bad for the mental health of the individual, but rather seeks to investigate how their specific characteristics (eg, genre, display device, and duration and frequency of playing) may have an impact on the efficacy of the game to improve players' well-being. In the future, it would be rather interesting to deeply investigate this topic; it would also be interesting to consider the specific characteristics of the players (eg, gender and gaming habits). In addition, future research should investigate the adoption of other commercial virtual reality systems with different characteristics in terms of immersion and interactions with the game, including other off-the-shelf virtual reality systems, such as Oculus Go (Facebook Technologies) or PlayStation VR (Sony Interactive Entertainment). These products are very appealing since, unlike the system tested in this study, they could be used easily even by nonexpert operators and are more budget friendly.

\section{Acknowledgments}

The authors would like to thank MSI Italy for supporting the study and providing PCs and hardware for data acquisition. In addition, the authors would like to thank all volunteers as well as the staff members Ambra Ferrari and Eleonora Maria Minissi for helping with data acquisition.

\section{Conflicts of Interest}

None declared.

\section{Multimedia Appendix 1}

Experimental setting of the study. 


\section{Multimedia Appendix 2}

Zero-order correlations between positive emotions, negative emotions, and anxiety scores $(\mathrm{N}=36)$.

[PNG File, 166 KB-Multimedia Appendix 2]

\section{Multimedia Appendix 3}

Mean scores of the positive and negative emotional states. Positive emotions are reported in the left-hand column and negative emotions are reported in the right-hand column. C1: Condition 1, Fruit Ninja VR first; and C2: Condition 2, Audioshield first. [PNG File, 129 KB-Multimedia Appendix 3]

\section{References}

1. Bowman ND, Tamborini R. "In the mood to game": Selective exposure and mood management processes in computer game play. New Media Soc 2013 Sep 24;17(3):375-393. [doi: 10.1177/1461444813504274]

2. Pallavicini F, Pepe A, Minissi M. Gaming in virtual reality: What changes in terms of usability, emotional response and sense of presence compared to non-immersive video games? Simul Gaming 2019 Mar 05;50(2):136-159. [doi:

$10.1177 / 1046878119831420]$

3. Rogers S. Forbes. 2019 Jun 21. 2019: The year virtual reality gets real URL: https://www.forbes.com/sites/solrogers/2019/ 06/21/2019-the-year-virtual-reality-gets-real/\#4e5610696ba9 [accessed 2019-10-03]

4. Lang B. Road to VR. 2019 Jun 06. Analysis: Monthly connected VR headsets on Steam pass 1 million milestone URL: https://www.roadtovr.com/monthly-connected-vr-headsets-steam-1-million-milestone/ [accessed 2019-10-03]

5. Munafo J, Diedrick M, Stoffregen TA. The virtual reality head-mounted display Oculus Rift induces motion sickness and is sexist in its effects. Exp Brain Res 2017 Mar;235(3):889-901. [doi: 10.1007/s00221-016-4846-7] [Medline: 27915367]

6. Pallavicini F, Ferrari A, Zini A, Garcea G, Zanacchi A, Barone G, et al. What distinguishes a traditional gaming experience from one in virtual reality? An exploratory study. In: Proceedings of the International Conference on Advances in Human Factors and Wearable Technologies (AHFE 2017). Cham, Switzerland: Springer International Publishing; 2017 Presented at: International Conference on Advances in Human Factors and Wearable Technologies (AHFE 2017); July 17-21, 2017; Los Angeles, CA p. 225-231. [doi: 10.1007/978-3-319-60639-2 23]

7. Slater M, Linakis V, Usoh M, Kooper R. Immersion, presence and performance in virtual environments: An experiment with tri-dimensional chess. In: Proceedings of the ACM Symposium on Virtual Reality Software and Technology. New York, NY: Association for Computing Machinery (ACM); 1996 Presented at: ACM Symposium on Virtual Reality Software and Technology; July 1-4, 1996; Honk Kong p. 163-172. [doi: 10.1145/3304181.3304216]

8. Michailidis L, Balaguer-Ballester E, He X. Flow and immersion in video games: The aftermath of a conceptual challenge. Front Psychol 2018;9:1682 [FREE Full text] [doi: 10.3389/fpsyg.2018.01682] [Medline: 30233477]

9. Weibel D, Wissmath B. Immersion in computer games: The role of spatial presence and flow. Int J Comput Games Technol 2011;2011:1-14. [doi: 10.1155/2011/282345]

10. Steuer J. Defining virtual reality: Dimensions determining telepresence. J Commun 1992;42(4):73-93. [doi: 10.1111/j.1460-2466.1992.tb00812.x]

11. Csikszentmihalyi M. Flow: The Psychology of Optimal Experience. New York, NY: Harper \& Row; 1990.

12. Nakamura J, Csikszentmihalyi M. The concept of flow. In: Csikszentmihalyi M, editor. Flow and the Foundations of Positive Psychology: The Collected Works of Mihaly. Dordrecht, the Netherlands: Springer Science+Business Media; Apr 2014:239-263.

13. Weibel D, Wissmath B, Habegger S, Steiner Y, Groner R. Playing online games against computer- vs human-controlled opponents: Effects on presence, flow, and enjoyment. Comput Human Behav 2008 Sep;24(5):2274-2291. [doi: 10.1016/j.chb.2007.11.002]

14. Cox J. What makes a blockbuster video game? An empirical analysis of US sales data. MDE Manage Decis Econ 2013 Apr 15;35(3):189-198. [doi: 10.1002/mde.2608]

15. Nacke LE, Drachen A, Göbel S. Methods for evaluating gameplay experience in a serious gaming context. Int J Comput Sci Sport 2010;9(2):1-12 [FREE Full text]

16. Feodoroff B, Konstantinidis I, Froböse I. Effects of full body exergaming in virtual reality on cardiovascular and muscular parameters: Cross-sectional experiment. JMIR Serious Games 2019 Aug 28;7(3):e12324 [FREE Full text] [doi: 10.2196/12324] [Medline: 31464194]

17. Farič N, Yorke E, Varnes L, Newby K, Potts HW, Smith L, et al. Younger adolescents' perceptions of physical activity, exergaming, and virtual reality: Qualitative intervention development study. JMIR Serious Games 2019 Jun 17;7(2):e11960 [FREE Full text] [doi: 10.2196/11960] [Medline: $\underline{\text { 31210135] }}$

18. Eggenberger P, Schumacher V, Angst M, Theill N, de Bruin ED. Does multicomponent physical exercise with simultaneous cognitive training boost cognitive performance in older adults? A 6-month randomized controlled trial with a 1-year follow-up. Clin Interv Aging 2015;10:1335-1349 [FREE Full text] [doi: 10.2147/CIA.S87732] [Medline: 26316729]

19. Pallavicini F, Pepe A. Taking neuropsychological test to the next level: Commercial virtual reality video games for the assessment of executive functions. In: Proceedings of the International Conference on Human-Computer Interaction (HCII 
2019). Cham, Switzerland: Springer; 2019 Presented at: International Conference on Human-Computer Interaction (HCII 2019); July 26-31, 2019; Orlando, FL p. 133-149. [doi: 10.1007/978-3-030-23563-5 12]

20. Reitan RM. Validity of the Trail Making Test as an indicator of organic brain damage. Percept Mot Skills 1958 Dec 01;8(3):271-276. [doi: 10.2466/pms.1958.8.3.271]

21. Shelstad WJ, Smith DC, Chaparro BS. Gaming on the Rift: How virtual reality affects game user satisfaction. In: Proceedings of the Human Factors and Ergonomics Society International Annual Meeting. 2017 Oct 20 Presented at: Human Factors and Ergonomics Society International Annual Meeting; October 9-13, 2017; Austin, TX p. 2072-2076. [doi: 10.1177/1541931213602001]

22. Tan C, Leong T, Shen S, Dubravs C, Si C. Exploring gameplay experiences on the Oculus Rift. In: Proceedings of the 2015 Annual Symposium on Computer-Human Interaction in Play (CHI PLAY '15). New York, NY: Association for Computing Machinery (ACM); 2015 Presented at: 2015 Annual Symposium on Computer-Human Interaction in Play (CHI PLAY '15); October 5-7, 2015; London, UK p. 253-263. [doi: 10.1145/2793107.2793117]

23. Pallavicini F, Pepe A. Comparing player experience in video games played in virtual reality or on desktop displays. In: Proceedings of the Annual Symposium on Computer-Human Interaction in Play (CHI PLAY '19). New York, NY: Association for Computing Machinery (ACM); 2019 Presented at: Annual Symposium on Computer-Human Interaction in Play (CHI PLAY '19); October 22-25, 2019; Barcelona, Spain p. 195-210. [doi: 10.1145/3341215.3355736]

24. Walch M, Frommel J, Rogers K, Schüssel F, Hock P, Dobbelstein D, et al. Evaluating VR driving simulation from a player experience perspective. In: Proceedings of the CHI Conference on Human Factors in Computing Systems (CHI '17). New York, NY: Association for Computing Machinery (ACM); 2017 Presented at: CHI Conference on Human Factors in Computing Systems (CHI '17); May 6-11, 2017; Denver, CO p. 2982-2989. [doi: 10.1145/3027063.3053202]

25. Roettl J, Terlutter R. The same video game in $2 \mathrm{D}, 3 \mathrm{D}$ or virtual reality: How does technology impact game evaluation and brand placements? PLoS One 2018 Jul 20;13(7):e0200724. [doi: 10.1371/journal.pone.0200724]

26. Ravaja N, Salminen M, Holopainen J, Saari T, Laarni J, Jarvinen A. Emotional response patterns and sense of presence during video games. In: Proceedings of the Third Nordic Conference on Human-Computer Interaction (NordiCHI '04). New York, NY: Association for Computing Machinery (ACM); 2004 Presented at: Third Nordic Conference on Human-Computer Interaction (NordiCHI '04); October 23-27, 2004; Tampere, Finland p. 339-347. [doi: 10.1145/1028014.1028068]

27. Olson CK. Children's motivations for video game play in the context of normal development. Rev Gen Psychol 2010;14(2):180-187. [doi: 10.1037/a0018984]

28. Olson CK. Are electronic games health hazards or health promoters? In: Kowert R, Quandt T, editors. The Video Game Debate: Unravelling the Physical, Social, and Psychological Effects of Video Games. New York, NY: Routledge; 2015:39-53.

29. Fredrickson BL, Levenson RW. Positive emotions speed recovery from the cardiovascular sequelae of negative emotions. Cogn Emot 1998 Mar 01;12(2):191-220 [FREE Full text] [doi: 10.1080/026999398379718] [Medline: 21852890]

30. Quoidbach J, Berry EV, Hansenne M, Mikolajczak M. Positive emotion regulation and well-being: Comparing the impact of eight savoring and dampening strategies. Pers Individ Dif 2010 Oct;49(5):368-373. [doi: 10.1016/j.paid.2010.03.048]

31. Greenglass ER, Fiksenbaum L. Proactive coping, positive affect, and well-being. Eur Psychol 2009 Jan;14(1):29-39. [doi: 10.1027/1016-9040.14.1.29]

32. Fredrickson BL. The broaden-and-build theory of positive emotions. Philos Trans R Soc Lond B Biol Sci 2004 Sep 29;359(1449):1367-1378 [FREE Full text] [doi: 10.1098/rstb.2004.1512] [Medline: 15347528]

33. Garland EL, Fredrickson B, Kring AM, Johnson DP, Meyer PS, Penn DL. Upward spirals of positive emotions counter downward spirals of negativity: Insights from the broaden-and-build theory and affective neuroscience on the treatment of emotion dysfunctions and deficits in psychopathology. Clin Psychol Rev 2010 Nov;30(7):849-864 [FREE Full text] [doi: 10.1016/j.cpr.2010.03.002] [Medline: 20363063]

34. Fredrickson BL. The role of positive emotions in positive psychology. The broaden-and-build theory of positive emotions. Am Psychol 2001 Mar;56(3):218-226 [ [FREE Full text] [doi: 10.1037//0003-066x.56.3.218] [Medline: 11315248]

35. Granic I, Lobel A, Engels RCME. The benefits of playing video games. Am Psychol 2014 Jan;69(1):66-78. [doi: 10.1037/a0034857] [Medline: 24295515]

36. Osmanovic S, Pecchioni L. Beyond entertainment: Motivations and outcomes of video game playing by older adults and their younger family members. Games Cult 2015 Sep 02;11(1-2):130-149. [doi: 10.1177/1555412015602819]

37. Shin M, Heard R, Suo C, Chow CM. Positive emotions associated with "Counter-Strike" game playing. Games Health J 2012 Oct;1(5):342-347. [doi: 10.1089/g4h.2012.0010] [Medline: 26192000]

38. Koepp MJ, Gunn RN, Lawrence AD, Cunningham VJ, Dagher A, Jones T, et al. Evidence for striatal dopamine release during a video game. Nature 1998 May 21;393(6682):266-268. [doi: 10.1038/30498] [Medline: $\underline{9607763]}$

39. Snodgrass JG, Lacy MG, Francois Dengah HJ, Fagan J, Most DE. Magical flight and monstrous stress: Technologies of absorption and mental wellness in Azeroth. Cult Med Psychiatry 2011 Mar;35(1):26-62. [doi: 10.1007/s11013-010-9197-4] [Medline: 21165683]

40. Wack E, Tantleff-Dunn S. Relationships between electronic game play, obesity, and psychosocial functioning in young men. Cyberpsychol Behav 2009 Apr;12(2):241-244. [doi: 10.1089/cpb.2008.0151] [Medline: 19006465] 
41. Russoniello CV, O'Brien K, Parks JM. The effectiveness of casual video games in improving mood and decreasing stress. J Cyber Ther Rehabil 2009;2(1):53-66 [FREE Full text]

42. Billieux J, Van der Linden M, Achab S, Khazaal Y, Paraskevopoulos L, Zullino D, et al. Why do you play World of Warcraft? An in-depth exploration of self-reported motivations to play online and in-game behaviours in the virtual world of Azeroth. Comput Human Behav 2013 Jan;29(1):103-109. [doi: 10.1016/j.chb.2012.07.021]

43. Sherry J, Lucas K, Greenberg B, Lachlan K. Video game uses and gratifications as predictors of use and game preference. In: Vorderer P, Bryant J, editors. Playing Video Games: Motives, Responses, and Consequences. New York, NY: Routledge; 2006:213-224.

44. Yang C, Liu D. Motives matter: Motives for playing Pokémon Go and implications for well-being. Cyberpsychol Behav Soc Netw 2017 Jan;20(1):52-57. [doi: 10.1089/cyber.2016.0562] [Medline: 28080150]

45. Bouchard S, Bernier F, Boivin E, Morin B, Robillard G. Using biofeedback while immersed in a stressful videogame increases the effectiveness of stress management skills in soldiers. PLoS One 2012;7(4):e36169 [FREE Full text] [doi: 10.1371/journal.pone.0036169] [Medline: 22558370]

46. Dennis-Tiwary TA, Egan LJ, Babkirk S, Denefrio S. For whom the bell tolls: Neurocognitive individual differences in the acute stress-reduction effects of an attention bias modification game for anxiety. Behav Res Ther 2016 Feb;77:105-117 [FREE Full text] [doi: 10.1016/j.brat.2015.12.008] [Medline: 26745621]

47. Dennis TA, O'Toole L. Mental health on the go: Effects of a gamified attention bias modification mobile application in trait anxious adults. Clin Psychol Sci 2014 Sep 01;2(5):576-590 [FREE Full text] [doi: 10.1177/2167702614522228] [Medline: 26029490]

48. Fagundo AB, Santamaría JJ, Forcano L, Giner-Bartolomé C, Jiménez-Murcia S, Sánchez I, et al. Video game therapy for emotional regulation and impulsivity control in a series of treated cases with bulimia nervosa. Eur Eat Disord Rev 2013 Nov;21(6):493-499. [doi: 10.1002/erv.2259] [Medline: 24092598]

49. Tárrega S, Castro-Carreras L, Fernández-Aranda F, Granero R, Giner-Bartolomé C, Aymamí N, et al. A serious videogame as an additional therapy tool for training emotional regulation and impulsivity control in severe gambling disorder. Front Psychol 2015;6:1721 [FREE Full text] [doi: 10.3389/fpsyg.2015.01721] [Medline: 26617550]

50. Naugle KE, Naugle KM, Wikstrom EA. Cardiovascular and affective outcomes of active gaming: Using the Nintendo Wii as a cardiovascular training tool. J Strength Cond Res 2014 Feb;28(2):443-451 [FREE Full text] [doi: 10.1519/JSC.0b013e31829999c3] [Medline: 23660574]

51. Fish MT, Russoniello CV, O’Brien K. Zombies vs anxiety: An augmentation study of prescribed video game play compared to medication in reducing anxiety symptoms. Simul Gaming 2018 May 04;49(5):553-566. [doi: 10.1177/1046878118773126]

52. Fish MT, Russoniello CV, O'Brien K. The efficacy of prescribed casual videogame play in reducing symptoms of anxiety: A randomized controlled study. Games Health J 2014 Oct;3(5):291-295. [doi: 10.1089/g4h.2013.0092] [Medline: 26192483]

53. Sosa A, Simon G, Sweetman R, Rupp M, Mcconnell D. Investigating superstitious beliefs in technology. In: Proceedings of the Human Factors and Applied Psychology Student Conference. 2015 Presented at: Human Factors and Applied Psychology Student Conference; April 3, 2015; Daytona Beach, FL URL: https://commons.erau.edu/cgi/viewcontent. cgi?article $=1037 \&$ context=hfap [doi: $10.1057 / 97811375288895]$

54. Stanhope J, Owens C, Elliott L. Stress reduction: Casual gaming versus guided relaxation. In: Proceedings of the Human Factors and Applied Psychology Student Conference. 2015 Presented at: Human Factors and Applied Psychology Student Conference; April 3, 2015; Daytona Beach, FL URL: https://commons.erau.edu/hfap/hfap-2015/papers/9/

55. Pallavicini F, Ferrari A, Garcea G, Zanacchi A, Mantovani F. Effectiveness of virtual reality survival horror games for the emotional elicitation: Preliminary insights using Resident Evil 7: Biohazard. In: Proceedings of the International Conference on Universal Access in Human-Computer Interaction (UAHCI). Cham, Switzerland: Springer Nature; 2018 Presented at: International Conference on Universal Access in Human-Computer Interaction (UAHCI); July 15-20, 2018; Las Vegas, NV p. 87-101. [doi: 10.1007/978-3-319-92052-8 8]

56. Pallavicini F, Ferrari A, Mantovani F. Video games for well-being: A systematic review on the application of computer games for cognitive and emotional training in the adult population. Front Psychol 2018;9:2127 [FREE Full text] [doi: 10.3389/fpsyg.2018.02127] [Medline: 30464753]

57. Heim M. Virtual reality and the tea ceremony. In: Beckmann J, editor. The Virtual Dimension: Architecture, Representation, and Crash Culture. New York, NY: Princeton Architectural Press; 1998:156-177.

58. Faric N, Potts HW, Hon A, Smith L, Newby K, Steptoe A, et al. What players of virtual reality exercise games want: Thematic analysis of web-based reviews. J Med Internet Res 2019 Sep 16;21(9):e13833 [FREE Full text] [doi: 10.2196/13833] [Medline: 31538951]

59. Levac D, Nawrotek J, Deschenes E, Giguere T, Serafin J, Bilodeau M, et al. Development and reliability evaluation of the Movement Rating Instrument for Virtual Reality Game Play. JMIR Serious Games 2016 Jun 01;4(1):e9 [FREE Full text] [doi: 10.2196/games.5528] [Medline: 27251029]

60. Basso JC, Suzuki WA. The effects of acute exercise on mood, cognition, neurophysiology, and neurochemical pathways: A review. Brain Plast 2017 Mar 28;2(2):127-152. [doi: 10.3233/bpl-160040]

61. Anderson E, Shivakumar G. Effects of exercise and physical activity on anxiety. Front Psychiatry 2013;4:27. [doi: 10.3389/fpsyt.2013.00027] [Medline: 23630504] 
62. Yeung RR. The acute effects of exercise on mood state. J Psychosom Res 1996 Feb;40(2):123-141. [doi: 10.1016/0022-3999(95)00554-4] [Medline: 8778396]

63. Powers MB, Asmundson GJG, Smits JAJ. Exercise for mood and anxiety disorders: The state-of-the-science. Cogn Behav Ther 2015;44(4):237-239 [FREE Full text] [doi: 10.1080/16506073.2015.1047286] [Medline: 26057087]

64. Landers DM, Petruzzello SJ. Physical activity, fitness, and health. In: Bouchard C, Shepard RJ, Brubaker PH, editors. Physical Activity, Fitness, and Health: International Proceedings and Consensus Statement. Champaign, IL: Human Kinetics Publishers; 1994:868-882.

65. O'Loughlin EK, Barnett TA, McGrath JJ, Consalvo M, Kakinami L. Factors associated with sustained exergaming: Longitudinal investigation. JMIR Serious Games 2019 Jul 31;7(2):e13335 [FREE Full text] [doi: 10.2196/13335] [Medline: 31368440]

66. Bird M, Clark B, Millar J, Whetton S, Smith S. Exposure to "exergames" increases older adults' perception of the usefulness of technology for improving health and physical activity: A pilot study. JMIR Serious Games 2015 Nov 27;3(2):e8 [FREE Full text] [doi: 10.2196/games.4275] [Medline: 26614263]

67. Simmich J, Deacon AJ, Russell TG. Active video games for rehabilitation in respiratory conditions: Systematic review and meta-analysis. JMIR Serious Games 2019 Feb 25;7(1):e10116 [FREE Full text] [doi: 10.2196/10116] [Medline: 30801256]

68. Li J, Erdt M, Chen L, Cao Y, Lee S, Theng Y. The social effects of exergames on older adults: Systematic review and metric analysis. J Med Internet Res 2018 Jun 28;20(6):e10486 [FREE Full text] [doi: 10.2196/10486] [Medline: 29954727]

69. Bianchi-Berthouze N, Kim W, Patel D. Does body movement engage you more in digital game play? And why? In: Proceedings of the 2nd International Conference on Affective Computing and Intelligent Interaction (ACII '07). Cham, Switzerland: Springer Nature; 2007 Presented at: 2nd International Conference on Affective Computing and Intelligent Interaction (ACII '07); September 12-14, 2007; Lisbon, Portugal p. 102-113. [doi: 10.1007/978-3-540-74889-2 10]

70. Bianchi-Berthouze N. What can body movement tell us about players? Engagement? In: Proceedings of Measuring Behavior 2012. 2012 Presented at: Measuring Behavior 2012; August 28-31, 2012; Utrecht, the Netherlands p. 94-97.

71. Li J, Theng Y, Foo S. Exergames for older adults with subthreshold depression: Does higher playfulness lead to better improvement in depression? Games Health J 2016 Jun;5(3):175-182. [doi: 10.1089/g4h.2015.0100] [Medline: 27135146]

72. Ho Y, Yang S. Defining exergames and exergaming. In: Proceedings of Meaningful Play 2010. 2010 Presented at: Meaningful Play 2010; October 21-23, 2010; East Lansing, MI p. 1-17 URL: https://meaningfulplay.msu.edu/proceedings2010/ mp2010_paper_63.pdf

73. Bogost I. Persuasive Games: The Expressive Power of Videogames. Cambridge, MA: MIT Press; 2010.

74. Li J, Theng Y, Foo S, Xu X. Exergames vs traditional exercise: Investigating the influencing mechanism of platform effect on subthreshold depression among older adults. Aging Ment Health 2018 Dec;22(12):1634-1641. [doi: 10.1080/13607863.2017.1385722] [Medline: 28984486]

75. Viana RB, Alves CL, Vieira CA, Vancini RL, Campos MH, Gentil P, et al. Anxiolytic effects of a single session of the exergame Zumba Fitness on healthy young women. Games Health J 2017 Dec;6(6):365-370. [doi: 10.1089/g4h.2017.0085] [Medline: 29077484]

76. Dhand N, Khatkar M. Statulator. Sample size calculator for comparing paired differences URL: http://statulator.com/ SampleSize/ss2PM.html [accessed 2019-10-03]

77. Aitken RC. Measurement of feelings using visual analogue scales. Proc R Soc Med 1969 Oct;62(10):989-993 [FREE Full text] [Medline: $\underline{4899510]}$

78. Luria RE. The validity and reliability of the visual analogue mood scale. J Psychiatr Res 1975 Apr;12(1):51-57. [doi: 10.1016/0022-3956(75)90020-5]

79. Bond A, Lader M. The use of analogue scales in rating subjective feelings. Br J Med Psychol 1974;47(3):211-218. [doi: 10.1111/j.2044-8341.1974.tb02285.x]

80. Gift AG. Visual analogue scales: Measurement of subjective phenomena. Nurs Res 1989;38(5):286-288. [Medline: 2678015]

81. Abend R, Dan O, Maoz K, Raz S, Bar-Haim Y. Reliability, validity and sensitivity of a computerized visual analog scale measuring state anxiety. J Behav Ther Exp Psychiatry 2014 Dec;45(4):447-453. [doi: 10.1016/j.jbtep.2014.06.004] [Medline: 24978117]

82. Spielberger CD, Gorsuch RL, Lushene GR, Vagg PR, Jacobs GA. Manual for the State-Trait Anxiety Inventory (Form Y). Palo Alto, CA: Consulting Psychologists Press; 1983.

83. Spielberger CD. State-Trait Anxiety Inventory. Hoboken, NJ: John Wiley \& Sons; 2010.

84. Spielberger C, Sydeman SJ, Owen AE, Marsh BJ. Measuring anxiety and anger with the State-Trait Anxiety Inventory (STAI) and the State-Trait Anger Expression Inventory (STAXI). In: Maruish ME, editor. The Use of Psychological Testing for Treatment Planning and Outcomes Assessment. 3rd edition. Hillsdale, NJ: Lawrence Erlbaum Associates; 1999:993-1021.

85. Rossi V, Pourtois G. Transient state-dependent fluctuations in anxiety measured using STAI, POMS, PANAS or VAS: A comparative review. Anxiety Stress Coping 2012 Nov;25(6):603-645. [doi: 10.1080/10615806.2011.582948] [Medline: 21827372]

86. Julian LJ. Measures of anxiety: State-Trait Anxiety Inventory (STAI), Beck Anxiety Inventory (BAI), and Hospital Anxiety and Depression Scale-Anxiety (HADS-A). Arthritis Care Res (Hoboken) 2011 Nov;63 Suppl 11:S467-S472 [FREE Full text] [doi: 10.1002/acr.20561] [Medline: 22588767] 
87. Research Randomizer. URL: https://www.randomizer.org/ [accessed 2020-05-30]

88. Cohen J. Statistical Power Analysis for the Behavioral Sciences. 2nd edition. Hillsdale, NJ: Lawrence Erlbaum Associates; 1988.

89. Baños RM, Etchemendy E, Farfallini L, García-Palacios A, Quero S, Botella C. EARTH of Well-Being system: A pilot study of an information and communication technology-based positive psychology intervention. J Posit Psychol 2014 Jun 23;9(6):482-488. [doi: 10.1080/17439760.2014.927906]

90. Felnhofer A, Kothgassner OD, Schmidt M, Heinzle A, Beutl L, Hlavacs H, et al. Is virtual reality emotionally arousing? Investigating five emotion inducing virtual park scenarios. Int J Hum Comput Stud 2015 Oct;82:48-56. [doi: 10.1016/j.ijhcs.2015.05.004]

91. Herrero R, García-Palacios A, Castilla D, Molinari G, Botella C. Virtual reality for the induction of positive emotions in the treatment of fibromyalgia: A pilot study over acceptability, satisfaction, and the effect of virtual reality on mood. Cyberpsychol Behav Soc Netw 2014 Jun;17(6):379-384. [doi: 10.1089/cyber.2014.0052] [Medline: 24892201]

92. Maples-Keller JL, Bunnell BE, Kim S, Rothbaum BO. The use of virtual reality technology in the treatment of anxiety and other psychiatric disorders. Harv Rev Psychiatry 2017;25(3):103-113 [FREE Full text] [doi: 10.1097/HRP.0000000000000138] [Medline: 28475502]

93. Repetto C, Gaggioli A, Pallavicini F, Cipresso P, Raspelli S, Riva G. Virtual reality and mobile phones in the treatment of generalized anxiety disorders: A phase-2 clinical trial. Pers Ubiquitous Comput 2011 Oct 2;17(2):253-260. [doi: 10.1007/s00779-011-0467-0]

94. Diener E. Subjective well-being: The science of happiness and a proposal for a national index. Am Psychologist 2000;55(1):34-43. [doi: 10.1037/0003-066x.55.1.34]

95. Fredrickson BL. Cultivating positive emotions to optimize health and well-being. Prev Treat 2000;3(1):1-25 [FREE Full text] [doi: 10.1037/1522-3736.3.1.31a]

96. Riva G, Baños RM, Botella C, Wiederhold BK, Gaggioli A. Positive technology: Using interactive technologies to promote positive functioning. Cyberpsychol Behav Soc Netw 2012 Feb;15(2):69-77. [doi: 10.1089/cyber.2011.0139] [Medline: 22149077]

97. Riva G, Baños RM, Botella C, Mantovani F, Gaggioli A. Transforming experience: The potential of augmented reality and virtual reality for enhancing personal and clinical change. Front Psychiatry 2016;7:164 [FREE Full text] [doi: 10.3389/fpsyt.2016.00164] [Medline: 27746747]

98. Norman D. Emotional Design: Why We Love (Or Hate) Everyday Things. New York, NY: Basic Books; 2007.

99. Baharom SN, Tan WH, Idris MZ. Emotional design for games: A framework for player-centric approach in the game design process. Int J Multimed Ubiquitous Eng 2014 Oct 31;9(10):387-398 [FREE Full text] [doi: 10.14257/ijmue.2014.9.10.37]

100. Desmet PM, Porcelijn R, van Dijk MB. Emotional design: Application of a research-based design approach. Knowl Technol Policy 2007 Sep 11;20(3):141-155 [FREE Full text] [doi: 10.1007/s12130-007-9018-4]

101. Triberti S, Chirico A, La Rocca G, Riva G. Developing emotional design: Emotions as cognitive processes and their role in the design of interactive technologies. Front Psychol 2017;8:1773 [FREE Full text] [doi: 10.3389/fpsyg.2017.01773] [Medline: 29062300]

102. Slater M, Steed A, McCarthy J, Maringelli F. The influence of body movement on subjective presence in virtual environments. Hum Factors 1998 Sep;40(3):469-477. [doi: 10.1518/001872098779591368] [Medline: 9849105]

103. Aymerich-Franch L. Presence and emotions in playing a group game in a virtual environment: The influence of body participation. Cyberpsychol Behav Soc Netw 2010 Dec;13(6):649-654. [doi: 10.1089/cyber.2009.0412] [Medline: 21142989]

104. Li J, Theng Y, Foo S. Effect of exergames on depression: A systematic review and meta-analysis. Cyberpsychol Behav Soc Netw 2016 Jan;19(1):34-42. [doi: 10.1089/cyber.2015.0366] [Medline: 26716638]

105. Russell W, Newton M. Short-term psychological effects of interactive video game technology exercise on mood and attention. Educ Technol Society 2008;11(2):294-308.

106. Jones CM, Scholes L, Johnson D, Katsikitis M, Carras MC. Gaming well: Links between videogames and flourishing mental health. Front Psychol 2014;5:260 [FREE Full text] [doi: 10.3389/fpsyg.2014.00260] [Medline: 24744743]

\section{Abbreviations}

EEG: electroencephalogram

FPS: first-person shooter

GLM: generalized linear model

HD: high definition

HDMI: high-definition multimedia interface

HMD: head-mounted display

MANOVA: multivariate analysis of variance

MSI: Micro-Star International

PET: positron emission tomography

STAI-Y1: State-Trait Anxiety Inventory, Form Y1 
TMT: Trial Making Test

VAS: Visual Analogue Scale

VAS-A: Visual Analogue Scale-anxiety

VAS-FE: Visual Analogue Scale-fear

VAS-HP: Visual Analogue Scale-happiness

VAS-SD: Visual Analogue Scale-sadness

VAS-SP: Visual Analogue Scale-surprise

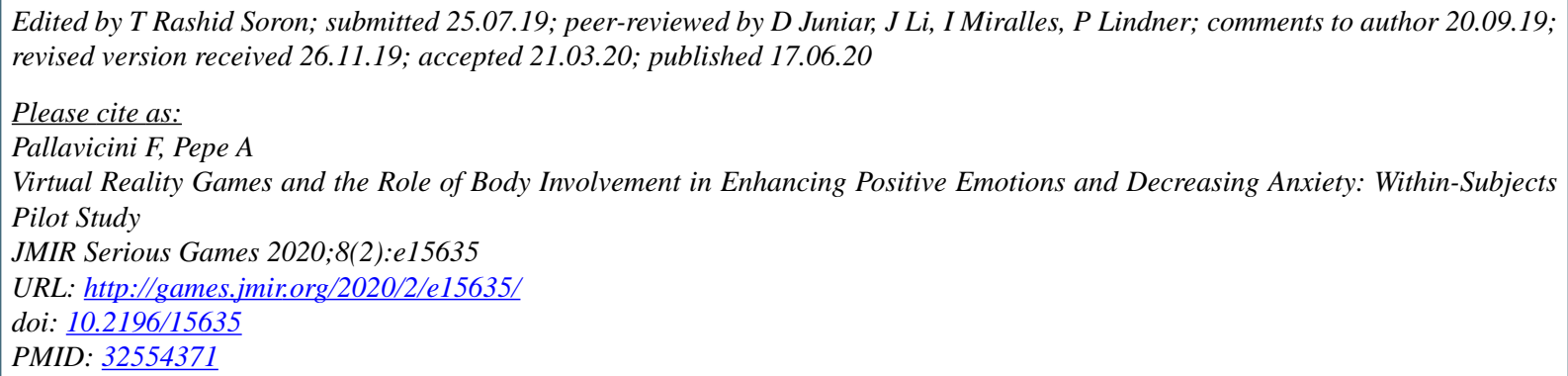

CFederica Pallavicini, Alessandro Pepe. Originally published in JMIR Serious Games (http://games.jmir.org), 17.06.2020. This is an open-access article distributed under the terms of the Creative Commons Attribution License (https://creativecommons.org/licenses/by/4.0/), which permits unrestricted use, distribution, and reproduction in any medium, provided the original work, first published in JMIR Serious Games, is properly cited. The complete bibliographic information, a link to the original publication on http://games.jmir.org, as well as this copyright and license information must be included. 